\title{
The dependence of positive binding energies on side chains - A theoretical prediction on the origin of regular ordering for the amino acid residues in the selectivity filter
}

\author{
Hongqi Ai ${ }^{a^{*}}$, Chong Zhang ${ }^{b}$, Yun $\mathrm{Li}^{a}$, Liang Zhang ${ }^{c}$, Fang $i^{a}$ \\ ${ }^{a}$ School of Chemistry and Chemical Engineering, University of Jinan, Jinan, 250022, P. R. China \\ ${ }^{b}$ Department of Chemistry and Technology, Liaocheng University, Liaocheng, 252059, P. R. China \\ ${ }^{c}$ Institute of Theoretical Chemistry, Shandong University, Jinan, 250100, P. R. China
}

*Author to whom correspondence should be addressed._E-mail address: chm_aihq@ujn.edu.cn

\section{Supporting information}

Table 1S The dipole moments (Debye) of these $\mathrm{GA}_{(\mathrm{L})} \mathrm{H}^{+} \mathrm{Nax}{ }^{+}$and $\mathrm{AGH}^{+} \mathrm{Na} x^{+}$dipeptides from the B3LYP/6-31G*.

\begin{tabular}{lcccccc}
\hline Complex & $\mathrm{GA}_{\mathrm{L}} \mathrm{H}^{+} \mathrm{Na}^{+}$ & $\mathrm{GA}_{\mathrm{L}} \mathrm{H}^{+} \mathrm{Na}^{+}$ & $\mathrm{GAH}^{+} \mathrm{Na}^{+}$ & $\mathrm{GAH}^{+} \mathrm{Na}^{+}$ & $\mathrm{AGH}^{+} \mathrm{Na}^{+}$ & $\mathrm{AGH}^{+} \mathrm{Na}^{+}$ \\
\hline $\begin{array}{l}\text { Dipole moments } \\
\text { Complex }\end{array}$ & $\begin{array}{c}11.3 \\
\mathrm{GA}_{\mathrm{L}} \mathrm{H}^{+} \mathrm{Li}^{+}\end{array}$ & $\begin{array}{c}9.6 \\
\mathrm{GA}_{\mathrm{L}} \mathrm{H}^{+} \mathrm{Li}^{+}\end{array}$ & $\begin{array}{c}15.6 \\
\mathrm{GAH}^{+} \mathrm{Li}^{+}\end{array}$ & $\begin{array}{c}9.6 \\
\mathrm{GAH}^{+} \mathrm{Li}^{+}\end{array}$ & $\begin{array}{c}9.3 \\
\mathrm{AGH}^{+} \mathrm{Li}^{+}\end{array}$ & $\begin{array}{c}14.0 \\
\mathrm{AGH}^{+} \mathrm{Li}^{+}\end{array}$ \\
\hline Dipole moments & 11.1 & 10.0 & 16.8 & 10.0 & 9.9 & 14.9 \\
\hline
\end{tabular}




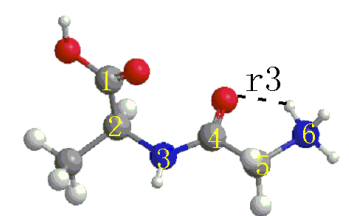

$\mathrm{GA}_{\mathrm{L}} \mathrm{H}^{+}$

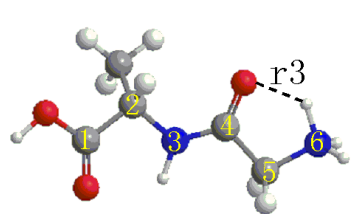

$\mathrm{GAH}^{+}$

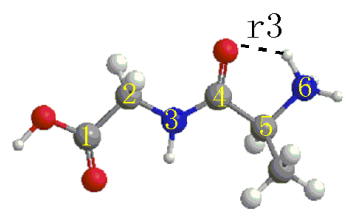

$\mathrm{AGH}^{+}$

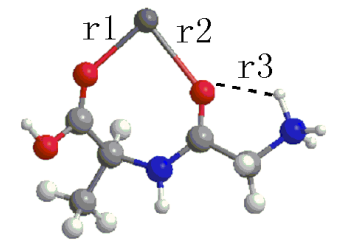

$\mathrm{GA}_{\mathrm{L}} \mathrm{H}^{+} \mathrm{M}^{\prime} 2^{+}$

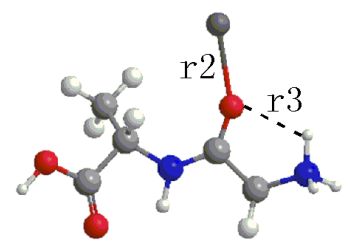

$\mathrm{GAH}^{+} \mathrm{M}^{\prime} 2^{+}$

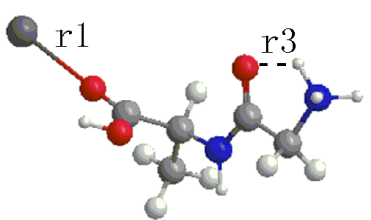

$\mathrm{GA}_{\mathrm{L}} \mathrm{H}^{+} \mathrm{K} 2^{+}$

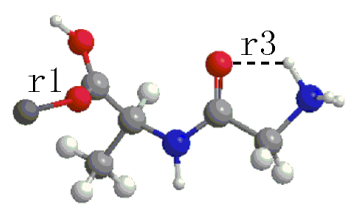

$\mathrm{GAH}^{+} \mathrm{M}^{+}$

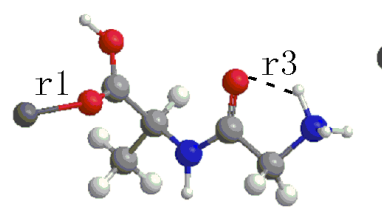

$\mathrm{GA}_{\mathrm{L}} \mathrm{H}^{+} \mathrm{M}^{\prime} 1^{+}$

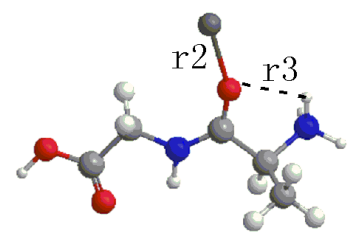

$\mathrm{AGH}^{+} \mathrm{M}^{+}$

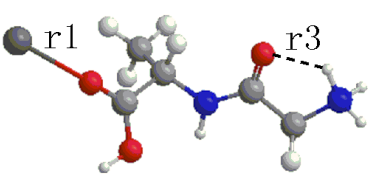

$\mathrm{GA}_{\mathrm{L}} \mathrm{H}^{+} \mathrm{K} 1^{+}$

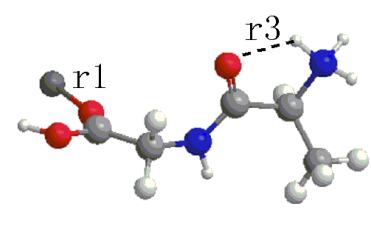

$\mathrm{AGH}^{+} \mathrm{M}^{+}$

Fig.1S B3LYP/6-31G*-optimized structures of $\mathrm{GA}_{(\mathrm{L})} \mathrm{H}^{+} \mathrm{M} x^{+}, \mathrm{AGH}^{+} \mathrm{Mx}^{+}\left(\mathrm{M}^{+}=\mathrm{M}^{\prime}+\mathrm{K}^{+}=\mathrm{Li}^{+}, \mathrm{Na}^{+}\right.$, $\mathrm{K}^{+} ; x=1$ or 2 ) and their reactants, $\mathrm{GA}_{(\mathrm{L})} \mathrm{H}^{+}$and $\mathrm{AGH}^{+}$. Those geometries, which change drastically and can not be denoted by the general form $\mathrm{GA}_{(\mathrm{L})} \mathrm{H}^{+} \mathrm{Mx}^{+}$or $\mathrm{AGH}^{+} \mathrm{Mx} x^{+}$, are shown separately with the specified $\mathrm{M}^{+}$. Hydrogen bonding in broken line. Distance in angstrom. 


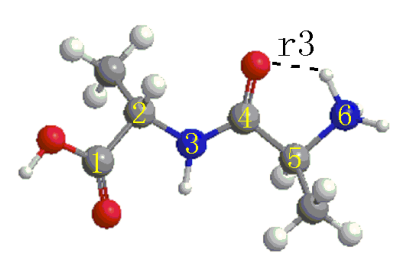

$\mathrm{AAH}^{+}$

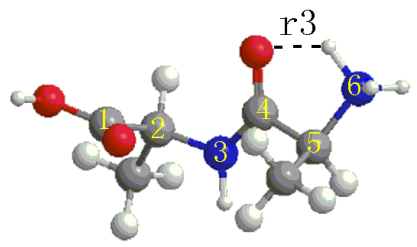

$\mathrm{AA}_{\mathrm{L}} \mathrm{H}^{+}$

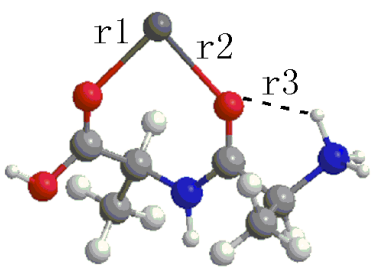

$\mathrm{AA}_{\mathrm{L}} \mathrm{H}^{+} \mathrm{M}^{\prime} 2^{+}$

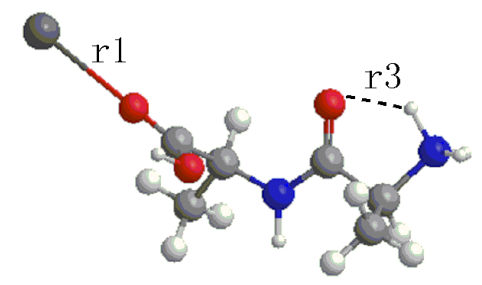

$\mathrm{AA}_{\mathrm{L}} \mathrm{H}^{+} \mathrm{K} 1,2^{+}$

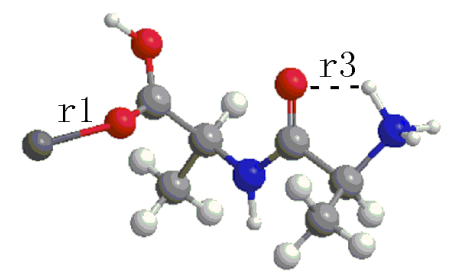

$\mathrm{AA}_{\mathrm{L}} \mathrm{H}^{+} \mathrm{M}^{\prime} 1^{+}$

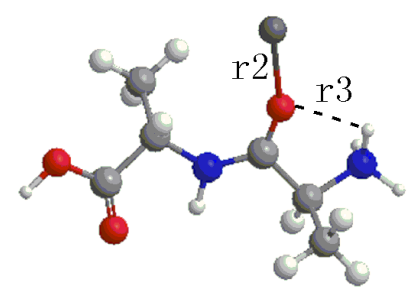

$\mathrm{AAH}^{+} \mathrm{M} 2^{+}$

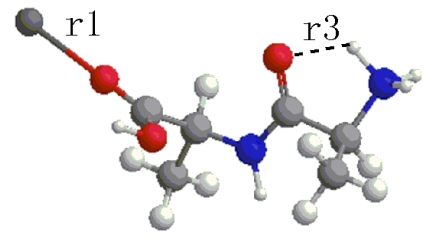

$\mathrm{AAH}^{+} \mathrm{Ml}^{+}$

Fig.2S B3LYP/6-31G*-optimized structures of $\mathrm{AA}_{(\mathrm{L})} \mathrm{H}^{+} \mathrm{M} x^{+}\left(\mathrm{M}^{+}=\mathrm{M}^{\prime}+\mathrm{K}^{+}=\mathrm{Li}^{+}, \mathrm{Na}^{+}, \mathrm{K}^{+} ; x=1\right.$ or 2$)$ and their reactants, $\mathrm{AA}_{(\mathrm{L})} \mathrm{H}^{+}$. Those geometries, which change drastically and can not be denoted by the general form $\mathrm{AA}_{(\mathrm{L})} \mathrm{H}^{+} \mathrm{M} x^{+}$, are shown separately with the specified $\mathrm{M}^{+}$. Hydrogen bonding in broken line. Distance in angstrom. 


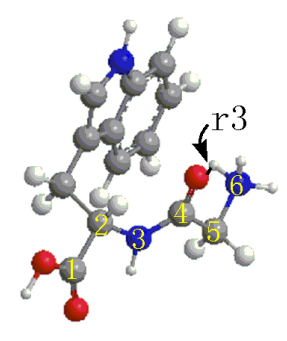

$\mathrm{GWH}^{+}$

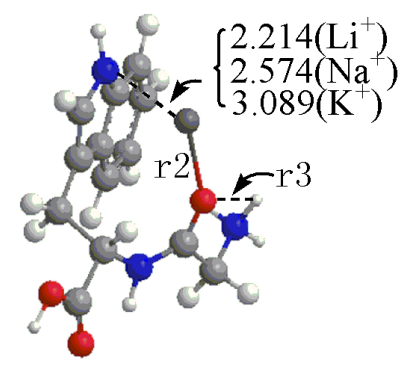

$\mathrm{GWH}^{+} \mathrm{M} 2$

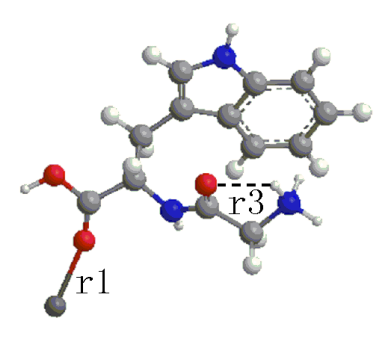

$\mathrm{GWH}^{\prime} \mathrm{Ml}^{+}$

Fig.3S B3LYP/6-31G*-optimized structures of $\mathrm{GWH}^{+} \mathrm{M} x^{+}\left(\mathrm{M}^{+}=\mathrm{M}^{+}+\mathrm{K}^{+}=\mathrm{Li}^{+}, \mathrm{Na}^{+}, \mathrm{K}^{+} ; x=1\right.$ or 2$)$ and their reactants, $\mathrm{GWH}^{+}$. Hydrogen bonding in broken line. Distance in angstrom. 


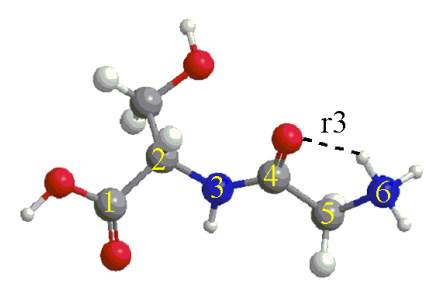

$\mathrm{GSH}^{+}$

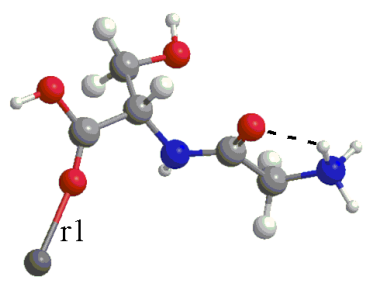

$\mathrm{GSH}^{+} \mathrm{Na} 1^{+} / \mathrm{K}^{+}$

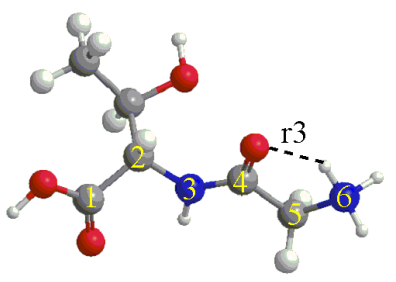

$\mathrm{GTH}^{+}$

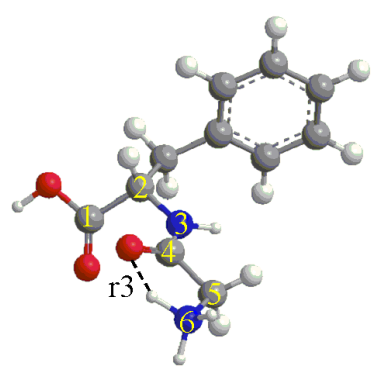

$\mathrm{GFH}^{+}$

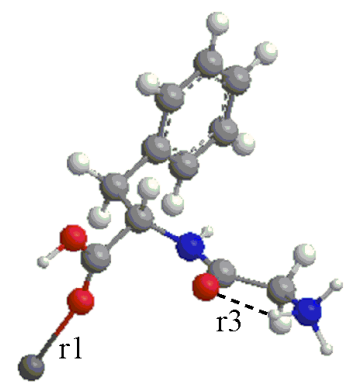

$\mathrm{GFH}^{+} \mathrm{Na}^{+} / \mathrm{K}^{+}$

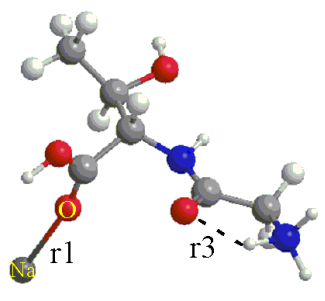

$\tau(\mathrm{OC} 1 \mathrm{C} 2 \mathrm{~N} 3)=51.7$

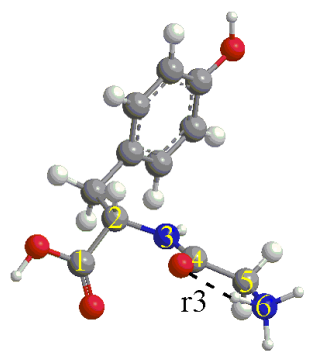

$\mathrm{GYH}^{+}$

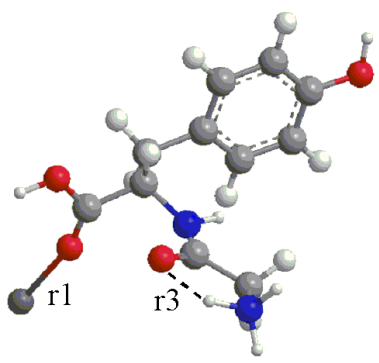

$\mathrm{GYH}^{+} \mathrm{Nal}^{+} / \mathrm{K}^{+}$

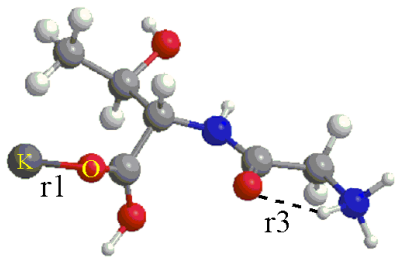

$\tau(\mathrm{OC} 1 \mathrm{C} 2 \mathrm{~N} 3)=145.4$

$\mathrm{GTH}^{\dagger} \mathrm{K}^{+}$

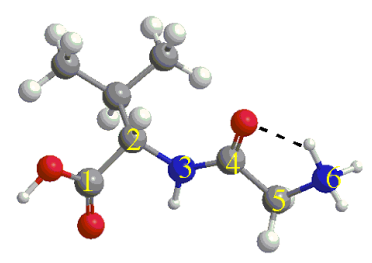

$\mathrm{GVH}^{+}$

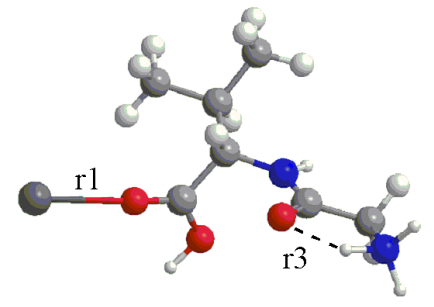

$\mathrm{GVH}^{+} \mathrm{Na}^{+} / \mathrm{K}^{+}$

Fig.4S B3LYP/6-31G*-optimized structures of $\mathrm{GSH}^{+} \mathrm{Na}^{+} / \mathrm{K}^{+}, \mathrm{GFH}^{+} \mathrm{Na}^{+} / \mathrm{K}^{+}, \mathrm{GYH}^{+} \mathrm{Na}^{+} / \mathrm{K}^{+}$, $\mathrm{GTH}^{+} \mathrm{Na}^{+} / \mathrm{K}^{+}$and $\mathrm{GVH}^{+} \mathrm{Na}^{+} / \mathrm{K}^{+}$and their each corresponding reactants $\mathrm{GSH}^{+}, \mathrm{GFH}^{+}, \mathrm{GYH}^{+}$, $\mathrm{GTH}^{+}$and $\mathrm{GVH}^{+}$. Hydrogen bonding in broken line. Distance in angstrom and dihedral angel in degree. 


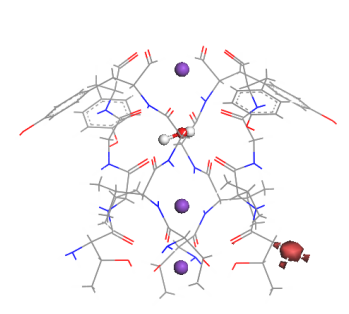

0

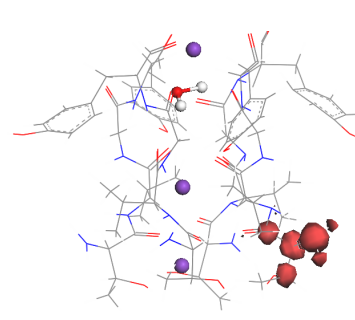

200
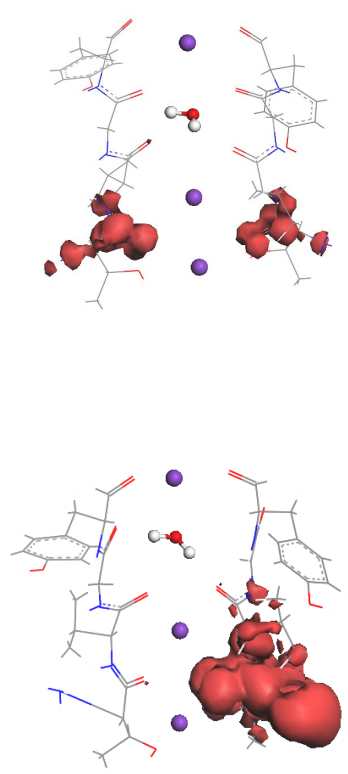

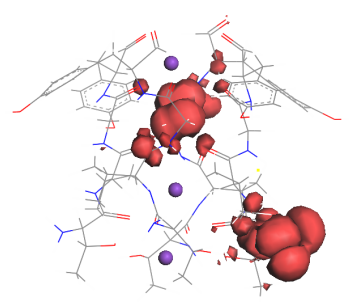

50

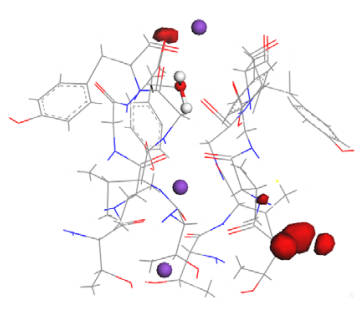

250
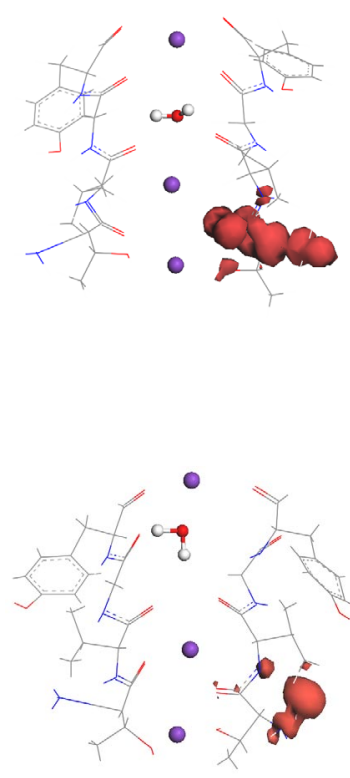

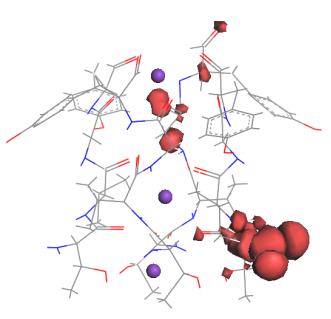

100

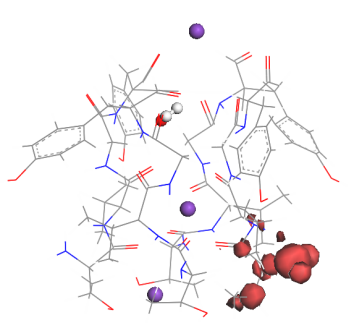

300

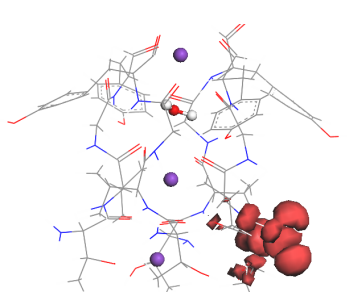

150
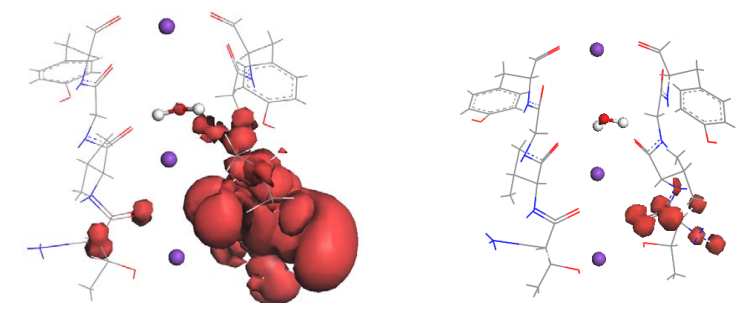

Fig.5S Seven states of the models $(1,2)$ (in wire format) including three $\mathrm{K}^{+}$ions and a water molecule (in ball and stick format) taken at $0,50, \ldots, 300 \mathrm{fs}$, respectively. Each EP is shown in crimson for model1 (first two lines, isovalue=1.6e-4) and model2 (last two lines, isovalue $=1.6 \mathrm{e}-6$ ). Three $\mathrm{K}^{+}$ions are in purple, nitrogen atoms in blue, carbon atoms in gray and hydrogen in white, respectively. 